\title{
Case Report \\ Benign Fibrous Histiocytoma of the Buccal Mucosa: Case Report and Literature Review
}

\author{
Paraskevi Giovani, ${ }^{1}$ Anna Patrikidou, ${ }^{1}$ Aris Ntomouchtsis, ${ }^{1}$ Soultana Meditskou, ${ }^{2}$ \\ Henri Thuau, ${ }^{3}$ and Kostas Vahtsevanos ${ }^{1}$
}

${ }^{1}$ Department of Maxillofacial Surgical Oncology, "Theagenio" Cancer Hospital, 2 Al. Simeonidi Street, 54007 Thessaloniki, Greece

${ }^{2}$ Laboratory of Histology, Embryology and Anthropology, Medical School, Aristotle University of Thessaloniki, 54124 Thessaloniki, Greece

${ }^{3}$ Craniofacial Unit, Chelsea and Westminster Hospital, London SW109NH, UK

Correspondence should be addressed to Anna Patrikidou, apatriki@otenet.gr

Received 17 March 2010; Accepted 24 May 2010

Academic Editor: David C. Howlett

Copyright ( $) 2010$ Paraskevi Giovani et al. This is an open access article distributed under the Creative Commons Attribution License, which permits unrestricted use, distribution, and reproduction in any medium, provided the original work is properly cited.

Benign fibrous histiocytoma is an interesting and challenging entity even in its most usual, cutaneous presentation. Noncutaneous presentation is extremely limited, even more so for the mucosa of the head and neck area. We herein report such a case, describing the clinical characteristics of the lesion, complete diagnostic evaluation, management, and follow-up. Diagnostic histopathological challenges are specifically illustrated. A complete review of the relevant literature is also included.

\section{Introduction}

The benign fibrous histiocytoma (BFH) is a mesenchymal tumour that has been described as a benign neoplasm composed of fibroblasts and histiocytes arising in the cutaneous and noncutaneous soft tissues [1]. Because of the confusion over the natural history of fibrohistiocytic lesions, BFH was not identified as a separate clinical entity until the 1960s [2]. Cutaneous BFH commonly originates in sun-exposed skin. Non-cutaneous BFH represents approximately $1 \%$ of all benign FH lesions [3], and most frequently occurs in the soft tissues in the lower extremities (50\%), less frequently in the upper extremities (20\%), retroperitoneum (20\%) [4].

The occurrence of this lesion in deep soft tissues of the head and neck has been rarely reported $[2,5]$. An exception to this is $\mathrm{BFH}$ arising in the orbital tissues, representing the most frequent primary mesenchymal tumour of the orbit in adult patients $[4,6]$. In the rest of the head and neck area, non-cutaneous BFH may arise in the buccal spaces, but cases of $\mathrm{BFH}$ of the tongue $[7,8]$, gingival or alveolar ridge $[9,10]$, mandible $[11]$, maxilla $[12]$, lower and upper lips, soft palate [13], and floor of the mouth have also been described [14]. Rare occurrences also include the nasal cavity and paranasal sinuses [15-17], larynx [18], trachea [19], temporomandibular joint [20], and submandibular and parotid glands [21-23]. It most often develops as a painless mass with specific symptoms caused by interference with the normal anatomy and physiology of the area in which they arise $[2,5]$. Interestingly, primary $\mathrm{BFH}$ has recently also been reported in the mandibular bone [24-26].

In contrast to malignant fibrous histiocytoma (MFH), benign fibrous histiocytoma of the noncutaneous soft tissues of the head and neck has received little attention in the head and neck surgical literature.

BFH is seen mainly in adults and most frequently in young and middle aged women. Patients are usually under 50 years of age and have a history of sun exposure, trauma, or chronic infection, suggesting that $\mathrm{BFH}$ is a reactive disease $[5,9,13]$.

This article describes a case of BFH of the buccal mucosa and discusses its clinical and pathological characteristics and management. 


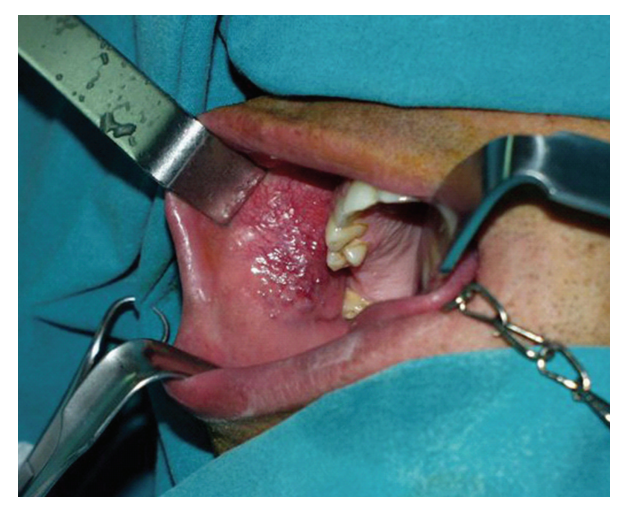

Figure 1: Buccal mucosa BFH: Preoperative view of the lesion.

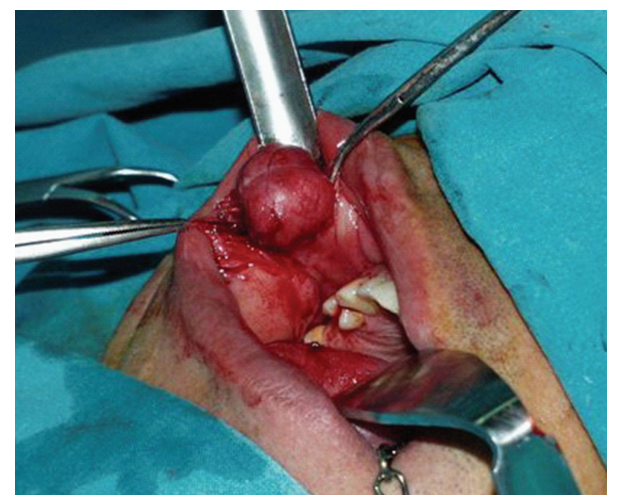

FIGURE 2: Buccal mucosa BFH: Intraoperative view of the lesion.

\section{Case Report}

A 36-year-old man was referred to the Department of Oral and Maxillofacial Surgery of "Theagenio" Cancer Hospital for an asymptomatic, slowly growing nodular lesion on the right buccal mucosa that had been present for approximately one year. His medical history was noncontributory. Examination revealed a well-circumscribed, moderately mobile, nontender fibroelastic lump of approximately $3 \mathrm{~cm}$ in diameter. The mucosal surface appeared smooth and moderately inflammatory, possibly due to local trauma (Figure 1).

The patient underwent an intraoral excision of the mass under general anesthesia with primary closure. On surgical excision the mass was easily dissected from the surrounding tissues (Figure 2).

Histologic analysis of the specimen revealed a macroscopically smooth, well-circumscribed encapsulated lesion of $2.4 \mathrm{~cm}$ in greatest dimension. The mass was grossly round in appearance, with a white grey surface (Figure 3 ). Microscopically the tumour was composed of fibroblast-like spindle cells with fascicular and focally storiform arrangement (Figure 4). Plump, polygonal histiocytic cells were found among the spindle cells. There were no mitotic figures, cellular pleomorphism, multinuclear giant cells, nuclear atypia or necrosis. The stroma was collagenised and demonstrated a rich vascularity. There was a scattered inflammatory infiltrate predominantly composed of lymphocytes and plasma cells.

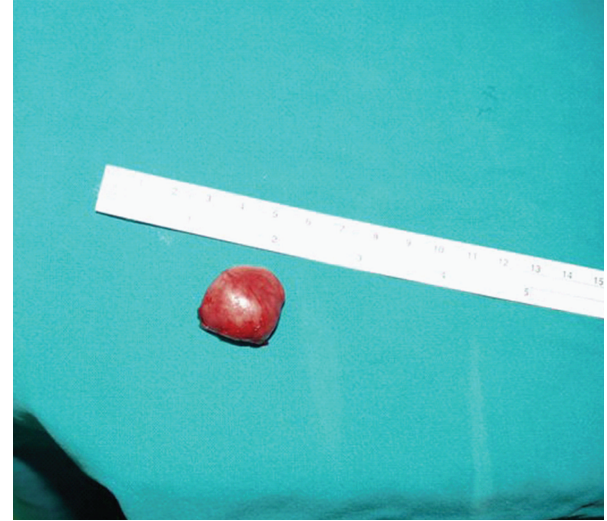

Figure 3: Buccal mucosa BFH: Surgical resection specimen.

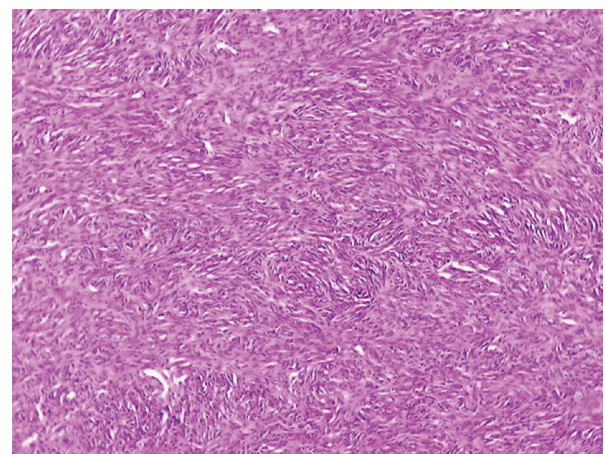

FIGURE 4: Spindle-shaped cells in a storiform pattern (H\&E stain, $\times 40$ ).

The tumour cells showed strong immunoreactivity for vimentin, weak and focal immunoreactivity for CD34 (Figure 5) and some tumour cells (histiocyte-like) were positive for CD68 (KP 1) (Figure 6). There was negativity for desmin, alpha smooth muscle actin ( $\alpha$-SMA), S-100 protein, Leu7, and CD117 (c-kit).

The final diagnosis was BFH. The patient was free of locoregional disease at 12-month follow-up.

\section{Discussion}

Pathologic analysis and diagnosis of this type of lesions is often challenging and usually based on a combination of light microscopy and immunohistochemistry [4].

Until recently the term fibrous histiocytoma $(\mathrm{FH})$ referred to both benign and malignant neoplasms. The differential diagnosis between the two entities was often difficult [4]. The so-called malignant FH is not a definable entity but instead represents a wastebasket of undifferentiated pleomorphic sarcomas accounting for no more than 5\% of adult soft tissue sarcomas. Although retained in the 2002 WHO classification of soft tissue tumours, it has long been recognised that these tumours have no relationship to true histocytes [27]. The benign fibrous histiocytoma also has a controversial diagnosis because of its uncertain histogenesis $[2,4,11]$. 


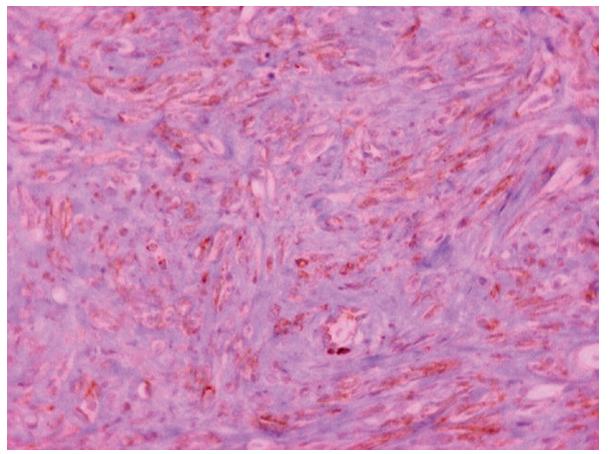

FIgure 5: Spindle-shaped tumour cells were positive for CD34 (diaminobenzidine, $\times 400$ ).

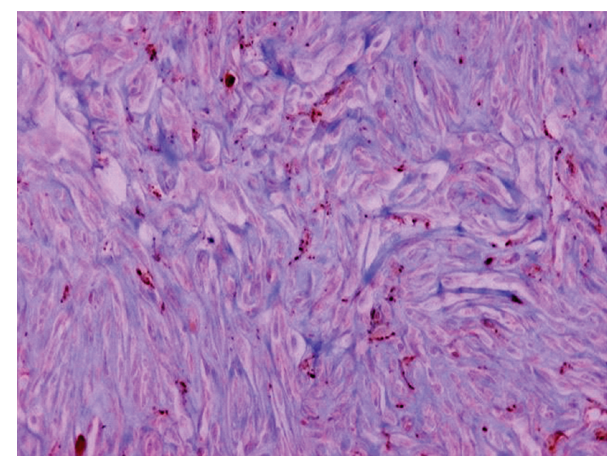

FIgURE 6: Histiocyte-like tumour cells were positive for CD68 (diaminobenzidine, $\times 400$ ).

Due to the lack of specific markers for fibrohistiocytic lesions, the diagnosis of BFH is generally based on the absence of markers for cells of other lineages [4]. Immunohistochemical staining and ultrastructural examination of the tumours and cell lines derived from them has revealed features of myoblastic and histiocytic differentiation as evidence of mesenchymal origin [4]. Immunostaining for CD68 can be found in any tumour-containing lysosomal granules or phagolysosomes as in our case [4]. Factor XIII $\alpha$ has occasionally been reported for BFH [28].

In the present study, the diagnosis was confirmed using immunostaining for vimentin (+), CD68 (+), CD34 (+), S$100(-)$, CD117 (-), Leu7 (-), desmin $(-)$, and $\alpha$-SMA $(-)$.

Histopathologically, BFH typically shows a biphasic cell population of histiocytes and fibroblasts [28]. In some cases the cells resemble myofibroblasts, primitive mesenchymal cells, and cells having intermediate or mixed features. The presence of a homogeneous population of fibroblast-like cells has also been described [2]. Our case showed biphasic population with predominance of fibroblast-like spindle cells. Other histological features frequently described in $\mathrm{BFH}$ are the presence of multinucleated giant cells, abundant vascularity, and inflammatory infiltrate [2]. The main differential diagnosis of oral $\mathrm{BFH}$ includes nodular fasciitis, solitary fibrous tumour (SFT), neurofibroma (NF), and dermatofibroma (DF) [29]. CD34 positivity is a useful aid for distinction between BFH and SFT, the former reported as
TABLE 1: Buccal mucosa BFH: review of the literature.

\begin{tabular}{|c|c|c|c|c|c|}
\hline Reference & Age (yr) & Sex & Treatment & $\begin{array}{l}\text { FU length } \\
\text { (months) }\end{array}$ & Outcome \\
\hline $\begin{array}{l}\text { O'Brien and } \\
\text { Stout, } 1964 \\
{[21]}\end{array}$ & 50 & F & LE & 24 & NED \\
\hline $\begin{array}{l}\text { Alonso del } \\
\text { Hoyo et al., } \\
1976 \text { [33] }\end{array}$ & * & $*$ & * & * & $*$ \\
\hline $\begin{array}{l}\text { Hoffman and } \\
\text { Martinez, } 1981 \\
\text { [9] }\end{array}$ & 8 & M & LE & 14 & NED \\
\hline $\begin{array}{l}\text { Bielamowicz et } \\
\text { al., } 1995 \text { [2] }\end{array}$ & 25 & M & LE & 24 & NED \\
\hline $\begin{array}{l}\text { Femiano et al., } \\
2001 \text { [4] }\end{array}$ & 32 & M & $\mathrm{LE}$ & $* *$ & $* *$ \\
\hline $\begin{array}{l}\text { Alves et al., } \\
2003 \text { [29] }\end{array}$ & 26 & $\mathrm{~F}$ & LE & 24 & NED \\
\hline
\end{tabular}

LE: Local excision; FU: Follow-up; NED: No evidence of disease.

* Full-text article not available to authors. Case reported in the Hoffman and Martinez (1981) paper [9]

** Information not available in the original article.

usually negative [8], although in our case the tumour showed weak immunoreactivity. Differentiation between BFH and NF can be based on S-100 positivity, more frequent mitoses and different fascicle configuration for the latter $[29,30]$. $\mathrm{BFH}$ and DF show similar immunoreactivity $[29,31]$. The negativity for SMA and S-100 could differentiate the lesion from leiomyosarcoma and neurogenic tumours [32].

The treatment of choice is the complete resection of tumour, with an excellent prognosis and recurrence rate of almost zero [31, 34]. Fewer than 5\% of cutaneous fibrous histiocytomas recur following local excision, and in the mouth most reported cases featured no recurrences [35]. $\mathrm{BFH}$ does not have metastatic potential $[31,34]$.

A review of the literature identified additional 6 cases of buccal mucosa BFH (Table 1). Most lesions were treated by a local excision without sacrificing structures that would cause major functional or cosmetic morbidity. One further paper reporting $\mathrm{BFH}$ of the oral mucosa was identified [36], however full-text article was not available to us for verification of the exact location of the tumours.

\section{Conclusion}

We reported the clinical, microscopic, and immunohistochemical aspects of a case of BFH of the buccal mucosa. Although rare, $\mathrm{BFH}$ must be considered in the differential diagnosis of oral soft tissue tumors.

The prognosis of $\mathrm{BFH}$ is excellent. The results of this study support local excision as definitive treatment of $\mathrm{BFH}$ of buccal mucosa. When pathologically clear margins are found, the incidence of local recurrence is unlikely. Incomplete excision or enucleation may result in significant percentage of recurrence [37]. Radiation therapy and chemotherapy have currently no role in the management of $\mathrm{BFH}$. 
A thorough knowledge of this lesion is important to the head and neck surgeon, who will provide the primary management of this rare lesion.

\section{Consent}

Written informed consent was obtained from the patient $\nu$ for publication of this case report and accompanying images. A copy of the written consent is available for review by the Editor-in-Chief of this journal.

\section{Competing Interests}

The authors declare that they have no competing interests.

\section{References}

[1] T.-C. Chen, T.-T. Kuo, and H.-L. Chan, "Dermatofibroma is a clonal proliferative disease," Journal of Cutaneous Pathology, vol. 27, no. 1, pp. 36-39, 2000.

[2] S. Bielamowicz, M. S. Dauer, B. Chang, and M. Zimmerman, "Noncutaneous benign fibrous histiocytoma of the head and neck," Otolaryngology: Head and Neck Surgery, vol. 113, no. 1, pp. 140-146, 1995.

[3] C. E. Skoulakis, C. E. Papadakis, G. E. Datseris, E. I. Drivas, D. E. Kyrmizakis, and J. G. Bizakis, "Subcutaneous benign fibrous histiocytoma of the cheek. Case report and review of the literature," Acta Otorhinolaryngologica Italica, vol. 27, no. 2, pp. 90-93, 2007.

[4] F. Femiano, C. Scully, G. Laino, and G. Battista, "Benign fibrous histiocytoma (BHF) of the cheek: CD 68-KP1 positivity," Oral Oncology, vol. 37, no. 8, pp. 673-675, 2001.

[5] A. Blitzer, W. Lawson, and H. F. Biller, "Malignant fibrous histiocytoma of the head and neck," Laryngoscope, vol. 87, no. 9, pp. 1479-1499, 1977.

[6] R. L. Font and A. A. Hidayat, "Fibrous histiocytoma of the orbit. A clinicopathologic study of 150 cases," Human Pathology, vol. 13, no. 3, pp. 199-209, 1982.

[7] A. G. Triantafyllou, A. D. Sklavounou, and G. G. Laskaris, "Benign fibrous histiocytoma of the oral mucosa," Journal of Oral Medicine, vol. 40, no. 1, pp. 36-38, 1985.

[8] P. A. Vargas, F. A. Alves, M. A. Lopes et al., "Solitary fibrous tumour of the mouth: report of two cases involving the tongue and cheek," Oral Diseases, vol. 8, no. 2, pp. 111-115, 2002.

[9] S. Hoffman and M. G. Martinez Jr., "Fibrous histiocytomas of the oral mucosa," Oral Surgery Oral Medicine and Oral Pathology, vol. 52, no. 3, pp. 277-283, 1981.

[10] M. Hidaka, A. Yamashita, K. Sakamoto, K.-I. Mukaisho, T. Hattori, and G. Yamamoto, "Benign fibrous histiocytoma occurred in the alveolar mucosa accompanying with sialidosis type 2 in Japanese infant," Oral Oncology Extra, vol. 41, no. 10, pp. 253-258, 2005.

[11] F. Ide and K. Kusama, "Benign fibrous histiocytoma: an additional case richly endowed with factor XIIIa cells," Oral Oncology, vol. 38, no. 3, pp. 321-322, 2002.

[12] A. E. Cale, P. D. Freedman, S. M. Kerpel, and H. Lumerman, "Benign fibrous histiocytoma of the maxilla," Oral Surgery Oral Medicine and Oral Pathology, vol. 68, no. 4, pp. 444-450, 1989.

[13] R. J. Fieldman and T. A. Morrow, "Fibrous histiocytomas of the soft palate," International Journal of Pediatric Otorhinolaryngology, vol. 18, no. 2, pp. 171-179, 1989.
[14] P. B. Gray, A. S. Miller, and M. J. Loftus, "Benign fibrous histiocytoma of the oral/perioral regions: report of a case and review of 17 additional cases," Journal of Oral and Maxillofacial Surgery, vol. 50, no. 11, pp. 1239-1242, 1992.

[15] D. H. Rice, J. G. Batsakis, J. T. Headington, and R. Boles, "Fibrous histiocytomas of the nose and paranasal sinuses," Archives of Otolaryngology, vol. 100, no. 5, pp. 398-401, 1974.

[16] K. H. Perzin and Y. S. Fu, "Non-epithelial tumors of the nasal cavity, paranasal sinuses and nasopharynx," Cancer, vol. 45, no. 10, pp. 2616-2626, 1980.

[17] T. Mentzel, H. Kutzner, A. Rütten, and H. Hügel, “Benign fibrous histiocytoma (dermatofibroma) of the face: clinicopathologic and immunohistochemical study of 34 cases associated with an aggressive clinical course," American Journal of Dermatopathology, vol. 23, no. 5, pp. 419-426, 2001.

[18] M. B. Jordan and J. V. Soames, "Fibrous histiocytoma of the larynx," Journal of Laryngology and Otology, vol. 103, no. 2, pp. 216-218, 1989.

[19] M. Hakimi, R. P. Pai, G. Fine, and J. C. Davila, "Fibrous histiocytoma of the trachea," Chest, vol. 68, no. 3, pp. 367-368, 1975.

[20] M. S. Lapayowker, W. T. Miller, W. M. Levy, and R. D. Harwick, "Pigmented villonodular synovitis of the temporomandibular joint," Radiology, vol. 108, pp. 313-316, 1973.

[21] J. E. O’Brien and A. P. Stout, "Malignant fibrous xanthoma," Cancer, vol. 17, pp. 1445-1455, 1964.

[22] J. C. Hutchinson Jr. and S. A. Friedberg, "Fibrous histiocytoma of the head and neck: a case report," Laryngoscope, vol. 88, no. 12, pp. 1950-1955, 1978.

[23] S. M. Shapshay, R. H. Wingert, and J. S. Davis, "Fibrous histiocytoma of the parotid gland," Laryngoscope, vol. 89, no. 11, pp. 1808-1812, 1979.

[24] M.-S. Heo, H.-J. Cho, K.-J. Kwon, S.-S. Lee, and S.-C. Choi, "Benign fibrous histiocytoma in the mandible," Oral Surgery, Oral Medicine, Oral Pathology, Oral Radiology, and Endodontics, vol. 97, no. 2, pp. 276-280, 2004.

[25] M. Kishino, S. Murakami, S. Toyosawa et al., "Benign fibrous histiocytoma of the mandible," Journal of Oral Pathology and Medicine, vol. 34, no. 3, pp. 190-192, 2005.

[26] W. Katagiri, M. Nakazawa, and M. Kishino, "Benign fibrous histiocytoma in the condylar process of the mandible: case report," British Journal of Oral and Maxillofacial Surgery, vol. 46, no. 1, pp. e1-e2, 2008.

[27] C. D. M. Fletcher, "The evolving classification of soft tissue tumours: an update based on the new WHO classification," Histopathology, vol. 48, no. 1, pp. 3-12, 2006.

[28] E. Calonje, T. Mentzel, and C. D. M. Fletcher, "Cellular benign fibrous histiocytoma: clinicopathologic analysis of 74 cases of a distinctive variant of cutaneous fibrous histiocytoma with frequent recurrence," American Journal of Surgical Pathology, vol. 18, no. 7, pp. 668-676, 1994.

[29] F. A. Alves, P. A. Vargas, S. A. Coelho Siqueira, R. D. Coletta, and O. P. De Almeida, "Benign fibrous histiocytoma of the buccal mucosa: case report with immunohistochemical features," Journal of Oral and Maxillofacial Surgery, vol. 61, no. 2, pp. 269-271, 2003.

[30] J. A. Regezi, R. J. Zarbo, C. E. Tomich, R. V. Lloyd, R. M. Courtney, and J. D. Crissman, "Immunoprofile of benign and malignant fibrohistiocytic tumors," Journal of Oral Pathology, vol. 16, no. 5, pp. 260-265, 1987.

[31] V. G. Prieto, J. A. Reed, and C. R. Shea, "Immunohistochemistry of dermatofibromas and benign fibrous histiocytomas," Journal of Cutaneous Pathology, vol. 22, no. 4, pp. 336-341, 1995. 
[32] C. D. M. Fletcher, P. Gustafson, A. Rydholm, H. Willén, and M. Åkerman, "Clinicopathologic re-evaluation of 100 malignant fibrous histiocytomas: prognostic relevance of subclassification," Journal of Clinical Oncology, vol. 19, no. 12, pp. 3045-3050, 2001.

[33] J. Alonso del Hoyo, F. Contreras, and F. D. Gonzalez, "Fibrohistiocytoma of the oral cavity," Revue de Stomatologie et de Chirurgie Maxillo-Faciale, vol. 77, no. 2, pp. 481-483, 1976.

[34] H. K. Hong, Y. K. Kim, and J. K. Park, "Benign fibrous histiocytoma of the floor of the mouth," Otolaryngology: Head and Neck Surgery, vol. 121, no. 3, pp. 330-333, 1999.

[35] E. Calonje and C. D. M. Fletcher, "Cutaneous fibrohistiocytic tumors: an update," Advances in Anatomic Pathology, vol. 1, pp. 2-15, 1994.

[36] W. Weerapradist and J. Punyasingh, "Fibrous histiocytoma: report of a case of the oral mucosa," The Journal of the Dental Association of Thailand, vol. 34, no. 5, pp. 263-269, 1984.

[37] B. C. Gleason and C. D. M. Fletcher, "Deep "benign" fibrous histiocytoma: clinicopathologic analysis of 69 cases of a rare tumor indicating occasional metastatic potential," American Journal of Surgical Pathology, vol. 32, no. 3, pp. 354-362, 2008. 


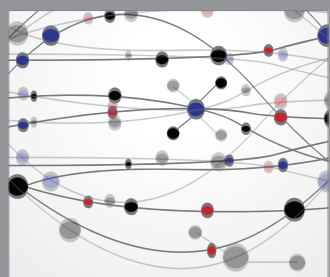

The Scientific World Journal
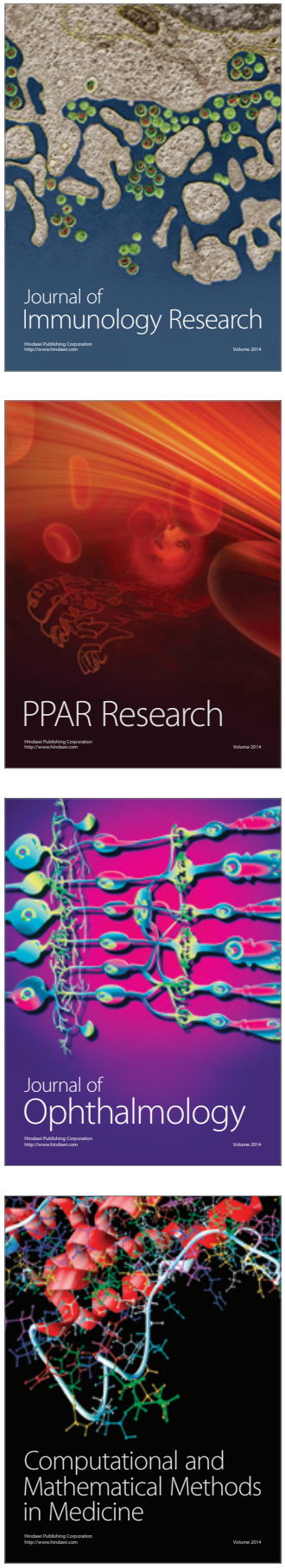

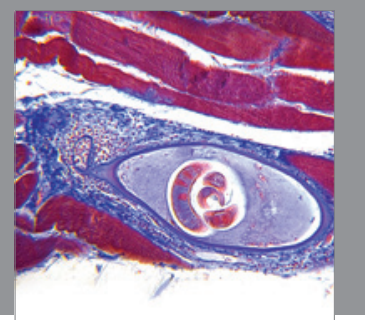

Gastroenterology

Research and Practice
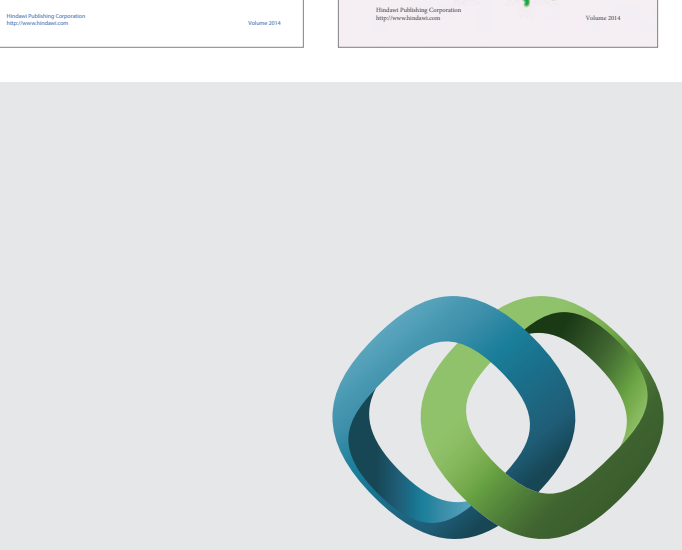

\section{Hindawi}

Submit your manuscripts at

http://www.hindawi.com
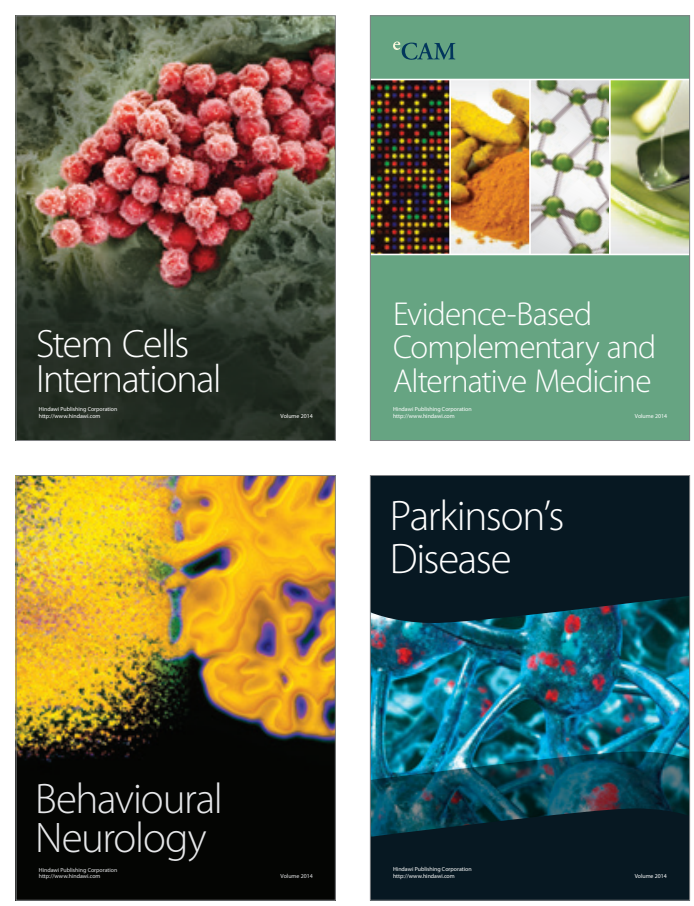

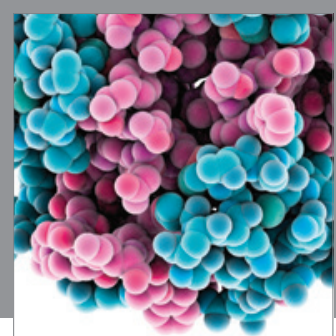

Journal of
Diabetes Research

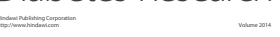

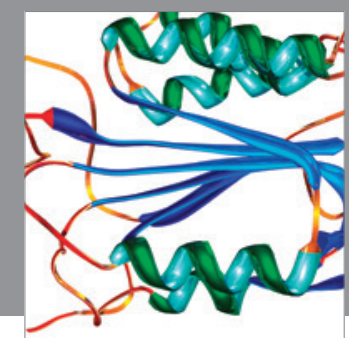

Disease Markers
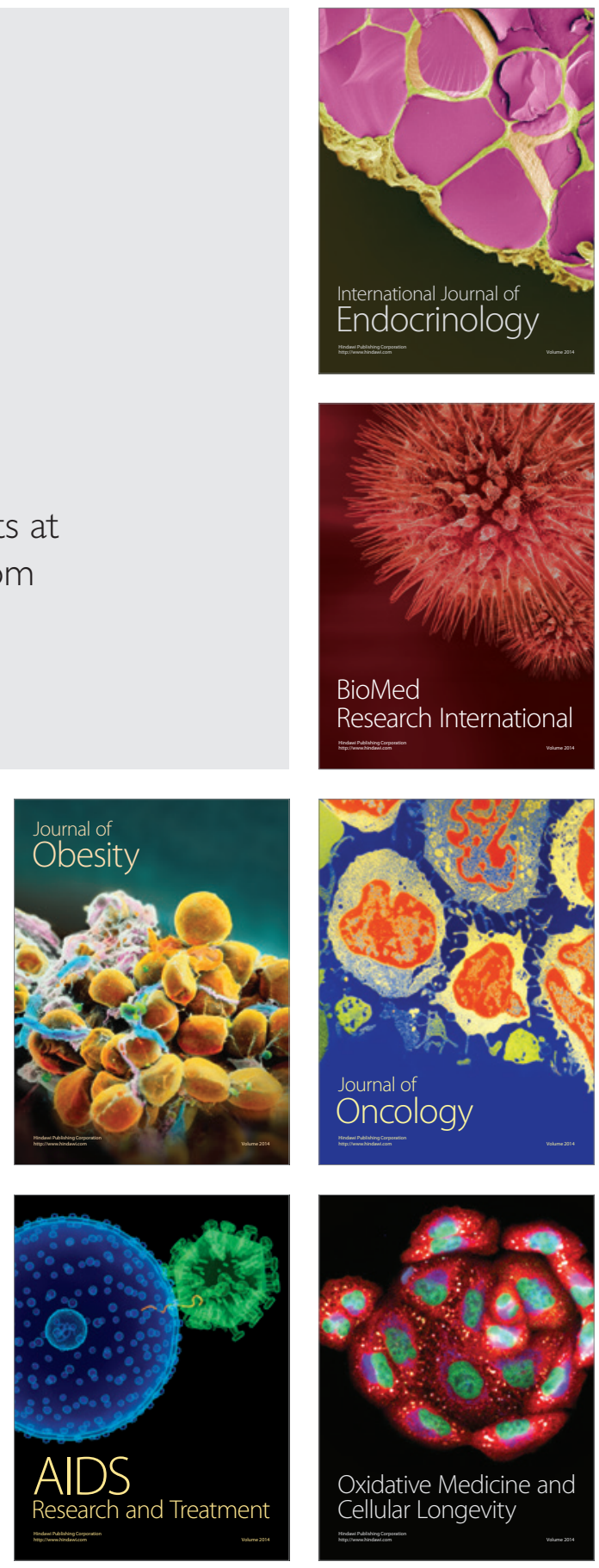